Published in final edited form as:

Curr Obes Rep. 2017 June ; 6(2): 163-167. doi:10.1007/s13679-017-0259-6.

\title{
The Report Card on BMI Report Cards
}

\author{
Hannah R. Thompson, PhD, MPH and \\ UC Berkeley School of Public Health, 2115 Milvia Street, 3rd Floor, Berkeley, CA 94704-1157, \\ Phone: 510-642-1263, Fax: 510-643-8197
}

Kristine A. Madsen, MD, MPH ${ }^{\mathrm{A}}$

UC Berkeley School of Public Health, 219 University Hall, \#7360, Berkeley, CA 94720-7360,

Phone: 510-664-9070, Fax: 510-643-6426

\begin{abstract}
Half of states in the U.S. have legislation requiring that schools conduct body mass index (BMI) screening among students; just under half of these states report results to parents. The effectiveness of school-based BMI screening and reporting in reducing childhood obesity is not established and the practice has raised concerns about the potential for increased weight-based stigmatization. Recent experimental studies of BMI screening and reporting have not demonstrated a positive impact on students' weight status. However, the language and formatting of BMI reports used in studies to date have been suboptimal and have likely limited the potential effectiveness of the practice. This article reviews the recent literature on school-based BMI screening and reporting and highlights important areas for future inquiry. The present review suggests that evidence to date is not sufficient to support definitive conclusions about the value of school-based BMI screening and reporting as a childhood obesity prevention tool.
\end{abstract}

\section{Keywords}

Body mass index (BMI); schools; screening; BMI reporting; overweight/obesity

\section{Introduction}

Childhood obesity persists as a major public health problem in the United States,[1] and disparities by race/ethnicity are increasing.[2] The National Academy of Medicine recommends school-based body mass index (BMI) screening and reporting as a tool to prevent and reduce pediatric obesity.[3] As of 2014, half of states $(n=25)$ had legislation requiring that schools monitor students' BMI, 11 (44\%) of which reported the results to parents.[4] Communicating students' weight status to parents/guardians via a notification letter or "BMI report card" could raise parents' awareness of their child's weight status and motivate positive action to improve their child's health.[5] While reporting BMI to parents is

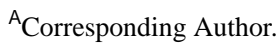

Compliance with Ethics Guidelines: Conflict of Interest: Hannah R. Thompson and Kristine A. Madsen declare they have no conflict of interest.

Human and Animal Rights and Informed Consent: This article does not contain any studies with human or animal subjects performed by any of the authors.
} 
a small-dose intervention, because of its widespread use, it is a potentially valuable public health tool for addressing childhood obesity. Understanding the impact of the practice is critical to inform both practice and policy.

The effectiveness of school-based BMI screening and reporting in reducing childhood obesity has yet to be established.[6-8] To date, studies examining BMI screening and reporting have not demonstrated a positive impact on students' weight status. However, best practices for reporting (e.g. using report language and formatting that is easy-to-understand) have not been employed.[9, 10] Further, the practice of school-based BMI screening and reporting has been controversial, and debate persists about the potential for unintended consequences related to weight stigmatization. $[4,5]$

While some reviews of school-based BMI screening and reporting have suggested that the potential harm from BMI screening and reporting may outweigh the possible benefits, [6, 7] the most recent review[4] concluded that these programs are vital components of schoolbased obesity prevention efforts and are valuable for schools, students, and parents. The present review aims to provide an updated comprehensive picture and interpretation of the evidence on BMI screening and reporting, including a discussion of controversies and potential best practices. We highlight important areas for future inquiry necessary to inform decision-making on the widespread use of school-based BMI screening and reporting as a childhood obesity prevention tool.

\section{The impact of BMI report cards on students' weight}

In their 2015 review, Ruggieri and Bass[4] highlighted findings on the effects of implementing BMI screening programs from studies in 7 states. Only 3 studies, coming from Pennsylvania, Arkansas, and California, assessed the impact of screening and reporting on students' weight status. The earliest study was from a single school district in Pennsylvania, which reported that prevalence of overweight students remained stable over the course of a 3-year screening program.[11] The lack of a control group made it difficult to draw conclusions about the effectiveness BMI reporting. The study from Arkansas, using data from the first 4 years of state-mandated BMI screening and reporting, demonstrated a halt in the progression of obesity.[12] However, during the same time period, Arkansas introduced several additional health-related initiatives, and similar trends in weight stabilization were seen nationally,[7] reducing confidence in BMI screening and reporting as the cause of improvements in students' weight status. The study from California found that BMI reporting did not reduce obesity for 5th, 7th, and 9th grade youth over the first 8 years in which BMI screening was instituted.[13] However, later research demonstrated that the reports used in California were difficult for parents to understand, did not use clear language to describe BMI, and did not provide actionable suggestions for parents whose children were identified as overweight.[9] Qualitative work on BMI reports has shown that parents would like reports to include actionable recommendations for improving their child's health.[14]

Since Ruggieri and Bass' 2015 review, several new studies examining the impact of BMI screening and reporting programs in schools have been published and are described in the following paragraphs. While none of these more recent studies showed a positive impact on 
children's BMI or weight status, each had limitations that preclude drawing definitive conclusions about the effectiveness of BMI screening and reporting.

A large quasi-experimental study using data from New York City public schools showed no effect of BMI reporting.[15] Among students with a baseline BMI just above or below the $85^{\text {th }}$ percentile, Almond et al found that being labeled "overweight" (those with a BMI just at or above the $85^{\text {th }}$ percentile), as opposed to "normal" weight (those with a BMI just below the $85^{\text {th }}$ percentile), had no beneficial impact on students' BMI the following year. Using the same regression discontinuity design among students with a BMI very close to the $95^{\text {th }}$ percentile, BMI reports labeling a student as "obese" as opposed to "overweight" similarly had no effect on BMI. Despite a strong design, this study does have two notable limitations. First, youth with a BMI very near the $85^{\text {th }}$ percentile generally do not appear overweight to their families.[16] Thus, a family receiving a BMI report saying their healthy-looking child is "overweight" may be disinclined to believe it. BMI reports may, therefore, have the least impact among those students closest to the $85^{\text {th }}$ percentile. The second limitation relates to the use of the term "obese." While students with a BMI near the $95^{\text {th }}$ percentile are likely to appear overweight, studies have demonstrated that many parents find the term "obese" offensive, $[14,17,18]$ which may reduce their likelihood of taking action based on such a report.

In Massachusetts, Li et al[19] reported that prevalence of overweight and obesity declined by $3 \%$ between 2009 and 2014, coincident with instituting statewide BMI screening and reporting in grades $1,4,7$, and 10. In stratified analyses, the largest differences between prevalence figures in 2009 and 2014 were seen among $1^{\text {st }}(-4.2 \%)$ and $4^{\text {th }}(-4.8 \%)$ grade students. The similar decline for grades 1 and 4 , taken together, do not lend support for a causal effect of BMI reports; by 2014, $4^{\text {th }}$ graders would have received a report in $1^{\text {st }}$ grade, but no $1^{\text {st }}$ grade student would have been exposed to a report (BMI assessments start in grade 1). Similar to Gee's findings in Arkansas,[20] Li et al saw no decline in prevalence among $10^{\text {th }}$ graders, which could reflect lesser impact of BMI reporting among older students. Importantly, the Massachusetts' reports also used the term "obese," which led to public backlash[21] and may have diminished the effectiveness of the report.

A randomized controlled trial from Mexico of BMI screening and reporting in primary schools demonstrated no detectable effects on students' BMI or weight after five months.[22] While BMI reporting is theorized to draw parents' attention to their child's weight status and motivate positive health-related action,[5] parents in this study did not report any significant changes in weight control behaviors following report receipt. The authors concluded that the information provided in the BMI reports was not enough to induce change in this context, and suggested future research to test the impact of BMI reports combined with specific actions parents could take to improve their child's weight (e.g. reduce portion sizes) on changes in BMI.[5]

A follow-up study from Arkansas using a difference-in-differences approach (in which changes in BMI between 10th and 12th grade were compared between students exposed to BMI screening and reporting versus a control group) similarly found no effect of BMI screening and reporting.[20] However, this study relied on students' self-reported BMI data, 
which is highly prone to bias.[21, 23] Further, it focuses on high-school age students, who have greater autonomy than younger students and may, therefore, be less influenced by a BMI report sent home to parents.

These recent studies have made important contributions to the evidence on the impact of school-based BMI screening and reporting. However, the studies lacked sufficient attention to the actual intervention - the report itself - to allow for a definitive statement on the value of BMI reports. The BMI reports from 3 of the 4 studies used the term "obese," despite qualitative evidence suggesting the term is off-putting to many parents, especially parents in low-income communities and communities of color.[10, 14, 24] Several recent qualitative studies involving predominantly African American and Latino parents have found that parents want reports that: 1) are clear and concise; 2) are easy-to-understand; 3 ) use nonstigmatizing language that is protective of students' well-being; and 4) provide actionable advice to improve child's health, especially advice relevant for the entire family.[10, 14, 17 , $25]$

To the extent the letters are difficult to understand (e.g., written at an inappropriate reading level), that resources to support families in helping their child reach a healthy weight are unavailable to low-income families, or that letters are sent home in English to non-English speaking parents, BMI reporting could increase weight-related health disparities. While Li's study in Massachusetts[19] documented a decline in obesity prevalence at the state level, prevalence in the poorest school districts remained unchanged, widening income-related disparities in prevalence of obesity. Although it is not clear that reductions in BMI were due to BMI reporting, the study timing was concurrent with the state's mandated BMI screening and reporting period. Rigorously testing culturally sensitive reports aimed at addressing the needs of low-income and racially diverse families could strengthen the effectiveness of BMI reports. An ongoing randomized trial of BMI screening and reporting (NIH R01HL120666) that developed a BMI report with parental input[14] may provide a better understanding of the effectiveness of BMI reports.

\section{Avoiding potential harm}

Numerous experts have raised concerns about the potential for BMI screening and reporting in schools to lead to unintended negative consequences, including increased weight-based stigmatization.[26-28] Anecdotal reports from public health practitioners, parents, and students, as well as case studies, highlight worries about the practice leading to teasing, disordered eating, and psychological damage.[29-31]

Research on the potential for BMI screening and reporting to increase weight-based stigmatization has been largely descriptive and suggests that parents are more worried about BMI screening and reporting in schools than students. Recent qualitative studies demonstrate caregivers are concerned that weighing students in school may lead to negative weight-related comments, [32] cause their child embarrassment[17] or negatively impact their self-esteem.[10, 25] Parents also report that unhealthy weight control behaviors increase subsequent to BMI reports,[32-34] (although no studies have assessed the persistence of these behaviors).

Curr Obes Rep. Author manuscript; available in PMC 2018 June 01. 
Recent evidence from studies involving students does not demonstrate the same level of concern about potential harms of BMI screening and reporting. In Oregon, $4^{\text {th }}-11^{\text {th }}$ grade students expressed generally neutral opinions about school-based BMI assessments.[35] Similarly, the vast majority (94\%) of $5^{\text {th }}$ grade Canadian youth in another study felt "okay" or "happy" about having their BMI measured in school.[36] Arkansas students in grades 10-12 who were exposed to repeated BMI screening and reporting through late adolescence did not report unintended consequences (such as increased use of weight control behaviors, including diet pills) compared to students who were not exposed to screening in late adolescence.[20]

BMI screening and reporting may increase weight-based stigmatization and lead to unintended consequences, but more evidence is needed to allow for truly informed discussions of risks versus benefits. The aforementioned ongoing randomized trial of BMI screening and reporting in California (NIH R01HL120666) is assessing unintended consequences such as increased weight-based teasing, unhealthy weight control behaviors, and body dissatisfaction. Findings from the California study will provide further evidence about students' perspectives on school-based BMI screening and reporting.

\section{The value of BMI surveillance in schools}

In their review from 2015, Ruggieri and Bass highlight the important distinction between collecting BMI for the purposes of screening versus surveillance. The evidence described thus far in the present review deals with the effectiveness of BMI collected for the purpose of screening, i.e., identifying an individual at risk in order to intervene and reduce subsequent negative outcomes. From a surveillance perspective, where individual treatment is not a goal, large-scale collection of BMI enables us to describe trends and changes in weight status over time and measure progress towards achieving health objectives.[4] While data collected by the Centers for Disease Control and Prevention, such as the National Health and Nutrition Examination Survey,[37] provide an invaluable means of surveillance at the national level, these data cannot provide insights into local and regional trends. Making more granular data available to researchers and decision makers can support informed program and policy implementation decisions, and can advance science. Future investigations could explore the effectiveness of using data as a means of channeling funding towards schools with the highest percentage of students at risk for overweight and obesity. However, if surveillance is to continue, it is important to ensure that screening practices do not cause harm to students or families.

\section{BMI screening and reporting and the school environment}

Given the important role social, environmental, and structural factors play in the development of obesity,[38] interventions comprised of education only (including letters informing parents of their children's weight status) are unlikely to meaningfully reduce pediatric obesity. Interventions that improve children's nutrition and physical activity environments are far more likely to have an impact on weight status. Combining BMI screening and reporting with other programs aimed at improving the school nutrition and physical activity environment could be synergistic. In Kearney, Nebraska, schools 
implemented several evidence-based physical activity and healthy eating strategies aimed at addressing childhood obesity, including a BMI screening, reporting, and referral program.

[39] Researchers saw a 15\% relative decrease in the prevalence of childhood obesity over the six-year period. While no control group was available, the decline in obesity is far greater than that seen nationally.[40] There is good evidence documenting the effectiveness of multi-faceted school-based interventions in reducing obesity; [41, 42] however, these interventions require significant investment and schools need additional resources to implement such programs. The question remains whether BMI reporting, a far less expensive but low-dose tool, can improve weight status in the absence of additional changes to children's environments.

\section{Conclusion}

BMI reports, in their current format, do not appear to positively impact student weight status and questions remain about their potential to cause harm to students. Additional research should examine the impact of BMI reports that use appropriate and easy-to-understand language, and that provide actionable suggestions to improve students' nutrition and physical activity. Future studies should simultaneously examine the potential unintended consequences of BMI screening and reporting in schools. Such evidence can inform the adoption and implementation of school policies and practices related to BMI screening and reporting.

\section{Acknowledgments}

The authors are supported by National Institutes of Health (NIH) grant R01HL120666.

\section{References}

1. Ogden CL, Carroll MD, Kit BK, Flegal KM. Prevalence of obesity and trends in body mass index among US children and adolescents, 1999-2010. JAMA. 2012; 307(5):483-90. [PubMed: 22253364]

2. Madsen KA, Weedn AE, Crawford PB. Disparities in peaks, plateaus, and declines in prevalence of high BMI among adolescents. Pediatrics. 2010; 126(3):434-42. [PubMed: 20713482]

3. Institute of Medicine of the National Academies. Preventing childhood obesity Health in the balance [Executive summary]. Washington, DC: The National Academies Press; 2005.

4**. Ruggieri DG, Bass SB. A comprehensive review of school-based body mass index screening programs and their implications for school health: do the controversies accurately reflect the research? The Journal of School Health. 2015; 85(1):61-72. Recent comprehensive review on BMI screening and reporting in schools. [PubMed: 25440454]

5. Dietz WH, Story MT, Leviton LC. Issues and implications of screening, surveillance, and reporting of children's BMI. Pediatrics. 2009; 124(Suppl 1):S98-101. [PubMed: 19720673]

6. Soto C, White JH. School Health Initiatives and Childhood Obesity: BMI screening and reporting. Policy Polit Nurs Pract. 2010; 11(2):108-14. [PubMed: 20679328]

7. Evans EW, Sonneville KR. BMI report cards: will they pass or fail in the fight against pediatric obesity? Curr Opin Pediatr. 2009; 21(4):431-6. [PubMed: 19444114]

8. Ikeda JP, Crawford PB, Woodward-Lopez G. BMI screening in schools: helpful or harmful. Health education research. 2006; 21(6):761-9. [PubMed: 17093140]

9. Madsen KA, Linchey J. School-based BMI and body composition screening and parent notification in California: methods and messages. The Journal of School Health. 2012; 82(6):294-300. [PubMed: 22568465] 
10*. Moyer LJ, Carbone ET, Anliker JA, Goff SL. The Massachusetts BMI letter: a qualitative study of responses from parents of obese children. Patient Education and Counseling. 2014; 94(2):210-7. Qualitative study with racially diverse parents of overweight and obese Massachusetts students who were part of state's mandated BMI screening and reporting program. [PubMed: 24290240]

11. Johnson A, Ziolkowski GA. School-based body mass index screening program. Nutrition Today. 2006; 41(6):274-79.

12. Thompson JW, Card-Higginson P. Arkansas' experience: statewide surveillance and parental information on the child obesity epidemic. Pediatrics. 2009; 124(Suppl 1):S73-82. [PubMed: 19720670]

13. Madsen KA. School-based BMI screening and parent notification: A statewide natural experiment. Archives of Pediatrics \& Adolescent Medicine. 2011; 165(11):987-92. [PubMed: 21727262]

14*. Thompson HR, Linchey JK, Madsen KA. Critical Elements of a School Report to Parents on Body Mass Index. Preventing Chronic Disease. 2015; 12:E136. Qualitative work with diverse group of California parents to inform best practices for BMI reporting. Reports will be used in a large-scale randomized controlled trial to test the impact and unintended consequences of BMI screening and reporting. [PubMed: 26312381]

15**. Almond D, Lee A, Schwartz AE. Impacts of classifying New York City students as overweight. Proc Natl Acad Sci U S A. 2016; 113(13):3488-91. Analysis involving more than 3,500,000 New York City students examining impact of BMI screening and reporting on student weight status. [PubMed: 26976566]

16. Doolen J, Alpert PT, Miller SK. Parental disconnect between perceived and actual weight status of children: a metasynthesis of the current research. J Am Acad Nurse Pract. 2009; 21(3):160-6. [PubMed: 19302692]

17. Ruggieri DG, Bass SB. African-American Parents' Knowledge and Perceptions About BMI Measurements, School-Based BMI Screening Programs, and BMI Report Cards: Results from a Qualitative Investigation and Implications for School-to-Parent Communication. J Racial Ethn Health Disparities. 2016; 3(2):320-30. [PubMed: 27271073]

18. Dietz WH, Story MT, Leviton LC. Introduction to issues and implications of screening, surveillance, and reporting of children's BMI. Pediatrics. 2009; 124(Suppl 1):S1-2. [PubMed: 19720663]

19*. Li W, Buszkiewicz JH, Leibowitz RB, Gapinski MA, Nasuti LJ, Land TG. Declining Trends and Widening Disparities in Overweight and Obesity Prevalence Among Massachusetts Public School Districts, 2009-2014. Am J Public Health. 2015; 105(10):e76-82. Although not designed to assess the impact of BMI reporting, this study assesses youth obesity prevalence in Massachusetts, coincident with the implementation of school-based screening and reporting. [PubMed: 26270317]

20**. Gee KA. School-Based Body Mass Index Screening and Parental Notification in Late Adolescence: Evidence From Arkansas's Act 1220. The Journal of Adolescent Health. 2015; 57(3):270-6. Arkansas has the country's longest-running, best-studied school-based BMI screening and reporting program and this study looks at the program's impact on student weight status in high school. [PubMed: 26115907]

21. Bidwell A. Massachusetts schools to stop sending 'fat letters'. US News and World Report. Oct 17.2013

$22 * *$. Prina S, Royer H. The importance of parental knowledge: evidence from weight report cards in Mexico. J Health Econ. 2014; 37:232-47. Randomized controlled trial assessing impact of BMI reporting in Mexican primary schools. [PubMed: 25132149]

23. Elgar FJ, Stewart JM. Validity of self-report screening for overweight and obesity. Evidence from the Canadian Community Health Survey. Can J Public Health. 2008; 99(5):423-7. [PubMed: 19009930]

24. Fitzgibbon ML, Beech BM. The role of culture in the context of school-based BMI screening. Pediatrics. 2009; 124(Suppl 1):S50-62. [PubMed: 19720668]

25. Keough L. Caregivers and underserved minority populations: Views and opinions of the role of schools in BMI screening, education, and communication. Journal of Health Disparities Research and Practice. 2015; 8(3):80-95. 
26. Cogan JC, Smith JP, Maine MD. The risks of a quick fix: a case against mandatory body mass index reporting laws. Eat Disord. 2008; 16(1):2-13. [PubMed: 18175229]

27. Crawford PB, Hinson J, Madsen KA, Neumark-Sztainer D, Nihiser AJ. An Update on the Use and Value of School BMI Screening, Surveillance, and Reporting. Childhood Obesity. 2012; 7(6):4419.

28. Grimmett C, Croker H, Carnell S, Wardle J. Telling parents their child's weight status: psychological impact of a weight-screening program. Pediatrics. 2008; 122(3):e682-8. [PubMed: 18762503]

29. Hayes, D. [Accessed on December 5, 2016 August 23, 2013] BMI Report Cards: More Harm Than Good?. The Huffington Post. 2013. Available at http://www.huffingtonpost.com/dayle-hayes-msrd/bmi-report-cards-more-harm-than-good_b_3797678.html

30. Portilla MG. Body mass index reporting through the school system: potential harm. Journal of the American Dietetic Association. 2011; 111(3):442-5. [PubMed: 21338746]

31. ABC News. [Accessed on December 5, 2016] 'Fat Letters' Worry Students, Parents and Experts. Sep 3. 2013 Available at https://gma.yahoo.com/blogs/abc-blogs/fat-letters-worry-studentsparents-experts-124101086--abc-news-health.html

32. Kaczmarski JM, DeBate RD, Marhefka SL, Daley EM. State-mandated school-based BMI screening and parent notification: A descriptive case study. Health Promotion Practice. 2011; 12(6):797-801. [PubMed: 22068272]

33. Lee J, Kubik MY. Child's Weight Status and Parent's Response to a School-Based Body Mass Index Screening and Parent Notification Program. J Sch Nurs. 2015; 31(4):300-5. [PubMed: 25377929]

34. Schwartz M. Parental Perceptions of Body Mass Index Notification: A Qualitative Study. The Journal of School Health. 2015; 85(10):714-21. [PubMed: 26331754]

35. Hunsberger M, McGinnis P, Beamer BA, Smith J. Student and Parental Perceptions of Schoolbased Body Mass Index Screening and Notification. Journal of Community Medicine and Health Education. 2014; S2:1-6.

36. Johnston JC, McNeil DA, Best M, MacLeod C. A growth status measurement pilot in four Calgary area schools: perceptions of grade 5 students and their parents. J Sch Nurs. 2011; 27(1):61-9. [PubMed: 21173090]

37. Centers for Disease Control and Prevention. [Accessed on December 5, 2016] The National Health and Nutrition Examination Survey. Available at https://www.cdc.gov/nchs/nhanes/

38. Cheng JK. Confronting the social determinants of health--obesity, neglect, and inequity. N Engl J Med. 2012; 367(21):1976-7. [PubMed: 23171094]

39. Heelan KA, Bartee RT, Nihiser A, Sherry B. Healthier School Environment Leads to Decreases in Childhood Obesity: The Kearney Nebraska Story. Child Obes. 2015; 11(5):600-7. [PubMed: 26440386]

40. Ogden CL, Carroll MD, Kit BK, Flegal KM. Prevalence of childhood and adult obesity in the United States, 2011-2012. JAMA. 2014; 311(8):806-14. [PubMed: 24570244]

41. Willi SM, Hirst K, Jago R, Buse J, Kaufman F, El Ghormli L, et al. Cardiovascular risk factors in multi-ethnic middle school students: the HEALTHY primary prevention trial. Pediatr Obes. 2012; 7(3):230-9. [PubMed: 22461375]

42. Gortmaker SL, Peterson K, Wiecha J, Sobol AM, Dixit S, Fox MK, et al. Reducing obesity via a school-based interdisciplinary intervention among youth: Planet Health. Archives of Pediatrics \& Adolescent Medicine. 1999; 153(4):409-18. [PubMed: 10201726] 